\title{
High Posterior Tibial Slope Influence Medial Meniscus Injuries in ACL Deficient Knees
}

\author{
IULIAN MARCU1*, ANA MARIA OPROIU2*, NICOLAE MIHAILIDE ${ }^{1}$ \\ ${ }^{1}$ Foisor Orthopedics Hospital Bucharest, 35-37 Ferdinand I Blvd., 021382, Bucharest, Romania \\ ${ }^{2}$ Carol Davila University of Medicine and Pharmacy, Bucharest, 39 Dionisie Lupu Str., 020021, Bucharest, Romania
}

\begin{abstract}
The purpose of the current study was to evaluate the correlation between the tibial slope and medial meniscus injury in anterior cruciate ligament deficient knees. A total of 223 patients with primary ACL injury admitted to Foisor Orthopedic Hospital between 2015-2016 were included in this study. The posterior tibial slope was evaluated on a lateral $x$-ray view of the knee and was defined as the angle between the line joining the tibial plateau and the line perpendicular to the longitudinal axis (the proximal tibial anatomical axis). Patients were divided into two groups depending on the posterior tibial slope ( $<9.9$ and $\geq 10)$, and a Chi square test was used to evaluate if there is any correlation between this and internal meniscus injuries, and Fisher's exact test was used to verify this. Overall medial meniscus lesions were found in $43.5 \%$ of the patients. The mean value of the posterior tibial slope was 11.19+/-2,685. After grouping patients in low and high group ( $<9.9$ and $\geq 10$ ), there were $66.8 \%$ in the high tibial slope group and $33.2 \%$ in the low group. In the high PTS group there were 93 patients with medial meniscus lesion (62.4\%), and 56 (37.6\%) without medial meniscus lesion. The mean posterior tibial slope was higher in the medial meniscus tear group (11.78 degrees), than mean PTS in the group without medial meniscus lesion (10.42 degrees). There was a strong correlation between high tibial slope and medial meniscus lesions $(p=0.015)$. The main finding of the current study is that there is a statistically significant correlation between posterior tibial slope higher than 10 degrees and internal meniscus tears.
\end{abstract}

Keywords: posterior tibial slope, medial meniscus injury, ACL lesion

Recently there is a high interest in the association between increased posterior tibial slope and medial meniscus tears in anterior cruciate ligament (ACL)deficientknee. It is well demonstrated that $A C L$ is a primary restrain in anterior tibial translation [1].

The association between posterior tibial slope and anterior tibial translation was also demonstrated by Dejour, who showed that anterior tibial translation in weight bearing stance correlates with posterior tibial slope and this is higher in ACL deficient knees[2]. The medial meniscus is thought to limit anterior tibial translation in ACL deficient knees primarily by its posterior horn acting as a wedge against the posterior aspect of the medial condyle[3]. The role of medial meniscus in resisting anterior tibial translation in ACL-deficient knees was also demonstrated by Shoemaker who showed greater tibial displacement after meniscectomy in loaded knees[4].

The objective of the current study was to evaluate the correlation between the posterior tibial slope and medial meniscus injury in ACL deficient knees. The hypothesis was that individuals with higher posterior tibial slope and $\mathrm{ACL}$ deficiency are at a greater risk of having medial meniscus tears than those with a low posterior slope and $A C L$ deficiency.

\section{Experimental part}

The current study is a retrospective study based on the data registered in the National Registry of Ligamentoplasty. It included 223 patients, who underwent primary ACL reconstruction at Foisor Orthopaedics Hospital between 2015-2016. The mean age at surgery was 30 years, with limits between 15 and 48 years. The exclusion criteria were represented by associated surgery such as HTO or revision ACL surgery. There were 182 males and 41 females ( 81.6 and $18.4 \%)$. The study was approved by the Institutional Review Board.
Demographic data and data about ACL and meniscal injuries were collected. All patients were evaluated according to a similar protocol which included anteroposterior, lateral and skyline views of the knee. The x-rays were evaluated using the hospital's PACS system[5], to view the radiographs and digitally measure the posterior tibial slope on the affected knee, which was done by a single observer. To determine the posterior tibial slope, a method previously described by Dejour was used [2]. A line is drawn down the proximal tibial anatomical axis on a true lateral radiograph which gives high reliability among the tibial axis[6]. Then a line is drawn from the peak anterior and posterior points on the medial tibial plateau. The posterior tibial slope is defined as the angle between the line tangent to the tibial plateau and the line perpendicular to the longitudinal axis (fig. 1).

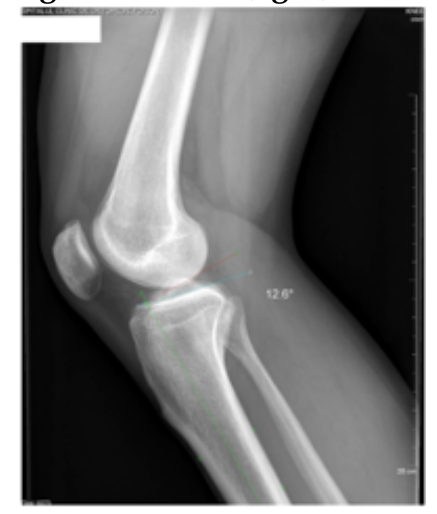

Fig. 1.

A total of $43.5 \%$ of the patients had a medial meniscus injury at the moment of surgery, and $16.6 \%$ had lateral meniscus injuries. Regarding posterior tibial slope values between 4 degrees and 16.2 degrees were found, with a mean value of $11.19+/-2.685$. There were $66.8 \%$ patients in the high tibial slope group and $33.2 \%$ in the low group. 
Because the average PTS measured on lateral radiographs is around 10.3 degrees[2] , the PTS limit was set at this value and, the ordinal values of the PTS were recoded in 2 nominal groups (<9.9degrees and $>=10 d e g r e e s)$. The presence of a medial meniscus injury was noted.

A Chi square test was used to search for correlation between nominal data, and it was verrifyed with a Fisher's exact test. The significance levels were set at a $p$ value $<0.05$.

\section{Results and discussions}

In the high PTS group, $62.4 \%$ of the patients had medial meniscus injury, and in the low PTSgroup there were $44.6 \%$ with this type of associated injury. The mean posterior tibial slope was higher in patients with the medial meniscus tear (11.78), than mean PTS in the group without medial meniscus lesion (10.42). There was a strong correlation between high posterior tibial slope and internal meniscus lesions which was statistically significant with a $p$ value of 0.011 .

The main finding of this study is that a high posterior tibial slope correlates with increased medial meniscus lesions in ACL deficient knees, and this is similar with data found by other authors[ 7 , who concluded that a PTS over 13 degrees is a risk factor for secondary medial meniscus injury in ACL deficient knees.

Markl et. all. in a study based on MRI measurement of posterior tibial slope found a higher incidence of meniscal injuries associated with higher tibial slope in $\mathrm{ACL}$ deficient knees. However in their study this correlation didn't reach statistical significance [8].

Medial meniscus lesions were found in $43.5 \%$ of the patients in the currentstudy, which is consistent with values found in similar studies[7]. The incidence of lateral meniscus injuries in our study is lower than the incidence found in other studies[ 7,9$]$, but is also consistent with the results found by Dejour[2], who found 15 lateral and 9 bilateral meniscal injuries in a group of 113 patients.

It is hard to set a limit to classify posterior tibial slope as high or low, because values between 7 and 13 are said to be normal $[10,11]$. In this study the values of the posterior tibial slope were between 4 degrees and 16.2 degrees, with a mean value of $11.19+/-2,685$, which is consistent with other literature studies $[2,7]$.

In the literature there isn't a consensus regarding radiographic measurement of the posterior tibial slope, because different longitudinal tibial axes are currently used[2,6,12-15]. Some authors are using the posterior tibial cortex axis as a reference for measuring the posterior slope[16], because it isn't influenced byage, sex, height or body mass as Brazier showed[6]. Others advocate for PTAA as a measuring reference $[2,7,15]$. However the values for posterior tibial slope measured with posterior tibial cortex as reference are smaller than the ones found by measuring it with proximal tibial anatomical axis[17], which may explain the values found in our study. Using the PACS system makes it easy and reliably to measure the posterior tibial slope[5]. Faschingbauer says that PTS can only be approximated on short lateral knee radiographs and the results will be with approximately 3 degrees too high [14].

After $\mathrm{ACL}$ reconstruction, a steep posterior tibial slope could place the graft and fixation material under increased loads during weight bearing, this representing a potential risk factor for early failure[17]. It is known that high tibial osteotomy can change the posterior tibial slope with medial open wedge decreasing it, and lateral closing wedge increasing it[ 18]. Neyret[ 19] describes a beneficial effect of decreasing tibial slope in $\mathrm{ACL}$ reconstruction combined with HTO by diminishing anterior tibial translation. Thus, the question arises whether or not an osteotomy for decreasing the posterior tibial slope would be beneficial or not in cases with excessively increase posterior tibial slope. Postma describes a high posterior tibial slope as a nonmodifiable risk factor for $\mathrm{ACL}$ injury together with notch stenosis, ligamentous laxity, hormonal function and neuromuscular maturation [20].

The tibial plateau is too complex to be characterized only by posterior tibial slope[21], which is a 2D measurement and the tibial plateau should be regarded as a 3D structure, with different posterior slope for the medial and lateral compartment. According to Hashemi [21], it is difficult to differentiate between medial and lateral aspects of the tibial plateau on a lateral radiograph and the true tibial slope should be measured at the center of the tibial plateau, and one should consider the measurement of the depth of medial compartment concavity to better characterize the complex three dimensional aspect of the tibial plateau.

The use of haptic actuators[22] could lower the recovery time after an ACL lesion and increase proprioception after ACL surgery. Moreover, haptic wearables can reduce knee loads by providing motion cues that alter risky walking patterns[23].

The main limitation of the current study is represented by the fact that the measurements were done by a single observer. However, the values found are consistent with those presented in similar studies $[2,7]$.

\section{Conclusions}

This current study demostrates that a high posterior tibial slope correlates with an increased rate of medial meniscus lesions.

\section{References}

1.BUTLER D.L., NOYES F.R., GROOD E.S., Ligamentous restraints to anterior-posterior drawer in the human knee. A biomechanical study. J Bone J oint Surg Am. 62, no.2, 1980,p.259-270

2. DEJ OUR H., BONNIN M., Tibial translation after anterior cruciate ligament rupture: two radiological tests compared. J Bone J oint Surg Br. 76, no.5, 1994, p.745-749.

3. ALLEN C.R., WONG E.K., LIVESAY G.A., SAKANE M., FU F.H., WOO S.L., Importance of the medial meniscus in ACL deficient knee. The Journal of Bone and J oint Surgery, 18, no.1, 2000, p.109-115

4. SHOEMAKER S.C., MARKOLF K.L., The role of the meniscus in the anterior-posterior stability of the loaded anterior cruciate-deficient knee. Effects of partial versus total excision. J Bone Joint Surg Am. 68, no.1, 1986, p.71.

5. STOICA I.C., MOGOS S., DRAGHICI A., CERGAN R., The medical and medicolegal use of the radiological image storage PACS for an orthopedic hospital. Rom J Leg Med. 25, no.2, 2017, p.235-238.

6. BRAZIER J., MIGAUD H., GOUGEON F., COTTEN A., FONTAINE C., DUQUENNOY A., Evaluation of methods for radiographic measurement of the tibial slope. A study of 83 healthy knees. Rev Chir Orthop Reparatrice Appar Mot. 82, no.3, 1996, p.195-200.

7. LEE J.J ., CHOI Y.J .,SHIN K.Y., CHOI C.H., Medial Meniscal Tears in Anterior Cruciate Ligament-Deficient Knees: Effects of Posterior Tibial Slope on Medial Meniscal Tears. Knee Surg Relat Res, 23, no.4, 2011, 227-230.

8. MARKL I., ZANTOP T., ZEMAN F., SEITZ J., ANGELE P., The effect of tibial slope in acute $A C L$-insufficient patients on concurrent meniscal tears. Arch Orthop Trauma Surg. 135, no. 8, 2015, p.1141.

9. HAGINO T., OCHIAI S., SENGA S., YAMASHITA T.,WAKO M., ANDO T.,

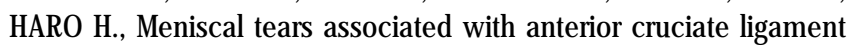
injury. Arch Orthop Trauma Surg. 135, no.12, 2015, p.1701.

10). BONIN N., AIT SI SELMI T., DEJOUR D., NEYRET P., Knee paraarticular flexion and extension osteotomies in adults. Orthopade, 33, no.2, 2004, p.193-200. 
11. ZENG C., CHENG L., WEI J., GAO S.G., YANG T.B., LUO W., LI Y.S., $X U$ M., LEI G.H. The influence of the tibial plateau slopes on injury of the anterior cruciate ligament: a meta-analysis. Knee Surg Sports Traumatol Arthrosc. 22, no.1, 2014, p.53-65

12. JULLIARD R., GENIN P. WEIL G., PALMKRANTZ P.,The median functional slope of the tibia. Principle. Technique of measurement. Value. Interest., Rev Chir Orthop Reparatrice Appar Mot, 79, no.8, 1993, p.625-634.

13. NOYES F.R., GOEBEL S.X., WEST J. Opening wedge tibial osteotomy: the 3-triangle method to correct axial alignment and tibial slope. Am J Sports Med, 33, no.3, 2005, p.378-387

14. FASCHINGBAUER M., SGROI M., JUCHEMS M., REICHEL H., KAPPE T. Can the tibial slope be measured on lateral knee radiographs?. Knee Surg Sports Traumatol Arthrosc., 22, no.12, 2014, p.3163 15. ZENG C., YANG T., WU S., GAO S.G., LI H., DENG Z.H.,ZANG Y., LEI G.H., Is posterior tibial slope associated with noncontact anterior cruciate ligament injury?. Knee Surg Sports Traumatol Arthrosc. 24, no.3, 2016, p.830

16. HOHMANN E., BRYANT A., REABURN P., TETSWORTH K., Does posterior tibial slope Influence knee functionality in the anterior cruciate ligament-deficient and anterior cruciate ligamentreconstructed knee?. The J ournal of Arthroscopic and Related Surgery, 26, no.11, 2010, p.1496-1502

17. FEUCHT M.J., MAURO C.S., BRUCKER P.U., IMHOFF A.B., HINTERWIMMER S., The role of the tibial slope in sustaining and treating anterior cruciate ligament injuries. Knee Surg Sports Traumatol Arthrosc., 21, no.1, 2013, p.134-145

18. CULLU E., AYDOGDU S., ALPARSLAN B., SUR H., Tibial slope changes following dome-type high tibial osteotomy. Knee Surg Sports Traumatol Arthrosc.,13, no.1, 2005, p.38-43

19. BOILEAU P., Neyret PH., Résultats des ostéotomies tibiales de valgisation associées aux plasties du ligament croisé antérieur dans le traitement des laxités antérieures chroniques évoluées. Journées lyonnaises de chirurgie du genou., 7, 1991, p. 232-249

20. POSTMA W.F., WEST R.V., Anterior Cruciate Ligament InjuryPrevention Programs. J Bone Joint Surg Am. 95, no.7, 2013, p.661 21. J AVAD HASHEMI, NAVEEN CHANDRASHEKAR, BRIAN GILL, BRUCE D. BEYNNON, J AMES R. SLAUTERBECK, ROBERT C. SCHUTT, HOSSEIN MANSOURI, EUGENE DABEZIES., The Geometry of the Tibial Plateau and Its Influence on the Biomechanics of the Tibiofemoral Joint. J Bone J oint Surg Am., 90, no.12, 2008, p. 2724-2734

22. P.L.MILEA, M. DASCALU, E. D. FRANTI, A. BARBILIAN, I.C. STOICA, Tactile Feedback Experiments for Forearm Prosthesis with Myoelectric Control. ROMJIST., 20, no.2, 2017, p. 101-114

23. PETER B. SHULL, DANA D. DAMIAN. Haptic wearables as sensory replacement, sensory augmentation and trainer - a review. J ournal of NeuroEngineering and Rehabilitation., 12, no.1, 2015, p.1

Manuscript received: 20.08 .2018 